\title{
A Critical Discourse Analysis of Language Used in Advertisements of Fairness Products in Pakistan
}

\author{
Iqra Kalsoom D/O Shoukat Ali \\ Department of Applied Linguistics, Government College University Faisalabad
}

\begin{abstract}
This research aims at exploring the language and rhetorical devices used by advertisers to make people and customers buy their products. The ads that have been put to analysis are of fairness products which have been selected from internet. The study falls into the realm of qualitative method. This study basically focuses the use of language in fairness products from the perspective of Critical Discourse Analysis. The findings indicate the vocabulary, language patterns, techniques and texts used by advertisers to manipulate the concept of beauty by forcing the point of view that only fair complexion in a symbol of beauty and the product is giving you the everlasting beauty. The study also explores that how these stereotypes and power over the audience in maintained by endorsing celebrities as an efficient tool for advertising.
\end{abstract}

Keywords: language, rhetorical devices, advertisements, fairness products, CDA, Fairclough's model

DOI: $10.7176 / \mathrm{NMMC} / 86-02$

Publication date: December $31^{\text {st }} 2019$

\section{Introduction}

The main focus of the study is on how people are influenced by the advertisement of the fairness products. Advertisement is a source of communication to encourage the sale of a product (Petly, Arens 2002). Consumers gain information about products and services through ads. After watching ads they feel that they are informed that which product is in their benefit and which is not. Ads of fairness products tend to use captivating language and beautiful models to sell their products and persuade the customers.

\subsection{Advertisements}

An advertisement, in a broad sense can be referred as to inform people about some product or service and persuade them to buy or avail it. Advertisements are part of our daily lives. It is a kind of communication. Advertisements have the ability to influence the audience. The consumers cannot escape the impact of advertisements. The study focuses on the use of linguistic tools in the advertisements of different types of fairness products. It attempts to study that which linguistic tools are used to make the discourses of the advertisements so powerful to affect the audience. It also attempts to study the role of advertisements in cultural imperialism and spreading complexes and biases regarding skin tones. Women in Pakistan mostly remain in their houses thus spend most of their time in watching TV or reading magazines etc. so the ads contribute a lot in shaping their belief system and changing their life styles. They easily get impressed by the celebrities advertising particular things and start following them in clothing, food habits, beauty products and hair styling etc. These ads also make people specially women class and brand conscious spending a lot of money buying expensive products just to cope with the race of looking rich and fashionable. Advertisements' aim is to construct or change people's opinion or belief about something or some issue. For this they use a number of techniques: they draw upon different genres and target upon specific population which is the focus of their product. Since every product is designed with certain type of users in mind, every commercial is orchestrated with some 'ideal audience' in mind (Fairclough, 1989).

Advertisements are identified as a separate genre, employing different types of strategies in order to persuade audience, inform them, influence them, warn, or even misinform or manipulate them to act in a certain way, e.g. to buy some product, or avoid a certain life style or to vote for some political party (Cook, 2001). The study also tries to reveal that whether these advertisements only persuade the audience or also manipulate them. The study also attempts to have a critical insight to understand the effect of these advertisements on society and culture of the target audience.

\subsection{Advertisements of Fairness Products}

There is a stream of television advertisements that emphasize and idealizes white complexion as a standard of feminine beauty. Advertisements for fairness products encourage the idea that beauty only means to be fair complexioned. Fairness is equal to beauty, self-confidence, security, love, marriage and career. In short social acceptance depends upon the colour of one's skin (Islam et al 2006; Karan 2008). Some advertisements have depressing cultural ideas and focuses on the measurement of a woman's beauty by the degree of fairness of their skin (Arif, 2006). No externally applied cream can change a person's skin colour (Karan 2008). 


\subsection{Critical Discourse Analysis}

This study took support of critical discourse analysis (CDA) and adopted Fairclough's (1995) three dimensional modal for the analysis of ads of fairness product in Pakistan. According to Van Dijk (2008), "Critical discourse analysis (CDA) is a type of discourse analytical research that primarily studies the way social power abuse, dominance and inequality are enacted, reproduced, and resisted by text and talk in the social and political context" (p. 85).

Fairclough (1992) designs Three Dimensional Model for discourse analysis. This is a cyclic model in manner. The first dimension is discourse as a text; text could be both in spoken or written form. The second dimension is discursive practice. Discursive practice further divided into following dimensions:

1) Producer of the text

2) Distributer/circulator of the text

3) Consumer of the text

The third dimension revolves around discourse as a social practice

\subsection{Purpose of the study}

The present study explores the role of advertisements in influencing the population. It also aims to raise awareness, so the people do not get persuaded by the use of language advertisements before buying any kind of fairness products. The study also exposes the representation of image of beauty through advertisements.

\subsection{Aims \& objectives of the study}

- To see the impacts of fairness advertisements on women in Pakistan

- To examine cultural deviation due to advertisements in Pakistan

- To inform masses about the normalizing power exercised by advertisers through advertisement discourse

- To bring the hidden aims and purposes of adverts to light

\subsection{Research questions}

1. What language patterns are used in fairness product advertisements in Pakistan to tempt the customers?

2. What are the impacts of fairness product advertisements on women in Pakistan?

\subsection{Significance of the Study}

People are usually persuaded by the media. The ad makers take benefit of this and make the advertisements to influence the people through attractive language and partial realities. This research makes the people conscious of the manipulating language of advertisements

\section{Review of the related studies}

In this segment, several previously conducted researches are reviewed which discussed linguistic features used in advertisement and Critical Discourse Analysis on advertisements. The study overviews in brief the research studies that deal with language features used in advertisements. Major works and contributions are cited with the intention of highlighting the impacts of language used in advertisements.

Iqbal, Danish \& Tahir (2014) examined advertisement of a beauty product through Critical Discourse Analysis Approach. This study basically focuses the language used in fairness cream "Fair \& lovely" and the strategies and techniques used by the product advertisers to influence and exploit the women. Language is a Discourse so Advertisements are form of media discourse. CDA tends to analyze the use of language, power and ideology in various contexts. Fiarclough's three-dimensional model is used which focuses on the representation and domination of beauty in women through advertisement of print media and mass media. The findings show the different life styles, texts by advertisers to manipulate and exploit the beauty; ideology of women by enforcing the point of view that product is giving you the everlasting beauty.

Najafian \& Ketabi (2011) investigate the application of Critical Discourse Analysis (CDA) approach of Fairclough (2003) and Social Semiotic Approach (SSA) proposed by Kress and van Leeuwen (2006) in analyzing the discourse of ads i.e. an approach that combines together textual analysis with semiotic analysis to study advertising. Two sample ads were taken from Time magazine $(2000,2001)$. As a result, two points emerged. The first is that advertising is a crucial factor in the emancipation of ideologies in any social discourses. The second is that this discourse is not neutral. This is mediated, means whatever is represented in the advertisement, pass through the linguistic (cohesion, disjunctive syntax, modality) as well as social semiotic resources (words, images and colours)

Shaikh Bughio \& Kadri (2015) investigated the social values, choices and ideologies that are produced and reinforced through advertisements. The study focuses on male and female representation differently through ads in order to serve gender inequality and dominance. The study has used critical discourse analysis (CDA) and 
semiotics as research tools. It helps researchers to analyse how different meanings and ideologies are constructed, processed and legitimised in social practices. It is based on Fairclough's three dimensional framework. The results showed that advertisements promote gender inequality. The advertisers use various strategies (textual and body features) in order to naturalize stereotypical roles of male and female.

Kaur, Arumugam \& Yunus (2013)'s study is very similar to current study. Beauty product advertisements in local Malaysian magazine were examined from a critical discourse analysis perspective. It analyzed the advertisement text to see the implications of the beauty product ads on society and to influence potential buyers. The analysis is based on Fairclough's three dimensional framework. It illustrates how the ideology of 'beauty' is produced and reproduced through advertisements in popular local women's magazines Cleo and Women's Weekly. The results tell that advertisers used various strategies to manipulate women. The ads promote an idealised life style and manipulate readers to believe that whatever is advertised is indeed true. The study revealed that how the ideology of beauty is constructed and reconstructed through magazines by creating the effect that how beauty products are synonymous with a better life. Advertising language is used to gain control over people's minds. Thus people in power (advertisers) use language as a means to exercise control over masses.

Another technique used by the advertisers to manipulate audience in discussed in a research conducted by Tehseem \& Hameed (2015). The study presents the concepts from feministic perspective by portraying celebrities as an effective tool for advertising. Celebrity endorsements play a significant role in advertisements. According to MEC Media Lab report 32\% consumers say that celebrity endorsement affect their decision to buy the product. It is believed that $75 \%$ products are being promoted by celebrities in India. Recent study proved that $35 \%$ consumers agreed that celebrities play a great role to make people trust a particular product.

Rosul (May 2011) found that people should not take everything for granted. They should inquire about the language of fairness ads because the ad makers use various techniques to make the ads. They use various linguistics elements for catching the attraction of the consumers. People should be aware of the hidden power of the discourses of ads. Fairness products ads claim to change skin color of consumers from black to white and their fate will be changed in this way and they will be able to achieve successes in every field of their life. The TVCs promote the idea that fairness is right equivalent to beauty, love and success. Being dark seems to be the source of many social problems. As a result, dark girls and boys suffer from inferiority complex. The advertisements exhibit their power through ideological text and visual images as well in the form of attractive models. Fairness product ads also make false or misleading statements.

Media adverts also portray women as sex objects (Riaz \& Tehseem 2015). This study explores that women are represented in a very negative manner in adverts. In adverts of Gillette a specific male brand women are portrayed as sex symbol. In all adverts of Gillette, women are presented just to attract male viewers towards their product, because there is no significance of woman in a male specific brand. In perfumes ads women are openly portrayed an object to satisfy sexual desires. The images of mostly girls are nude. So it is clear that portrayal of women in adverts limits their role just as sex symbol so that they can attract viewers by their looks which is highly immoral and against the dignity of women.

Khalid \& Baig (2016) explains that the advertisers play with the minds of consumers by using their cultural knowledge and social structures. They not only promote their brand and product in TVCs but also validate the patriarchal stereotypes. In the gender based TVCs, women are shown as physically and emotional weak, subservient, and passive housewives. On the other hand, the men are shown as strong, physically as well as emotionally powerful, more rational, bread winner, and dominant personality. The study suggested that the advertisement should be unbiased and the advertisers should play role to eradicate gender inequality from the society, minimization of gender gap and promotion of a prosperous and just society.

Ali, Naz, Aftab, \& Danish (2014) discussed that visual images in commercial advertisement of lux which is a multi-national brand of soap, represent the women in multi-national brand as imposition of new identity. The article investigates that representation of women in such adverts are against the women ideology and cultural norms in traditional Pakistani society. It is tried to reveal the hidden meanings produced in our cultural landscape through semiotic analysis of selected TV advertisements. Commercial advertisement of LUX 2014 starring Indian actors and actresses was selected.This study explored how multinational brand of lux is transforming traditional Pakistani women into modernized, bold and glamorous new age women. Study revealed that presentation of foreign culture in such adverts is contaminating Pakistani culture and its social norms and values.

Ullah \& khan (2014) argue about the objective representation of women in TV ads in Pakistan. The research is qualitative in nature employed critical discourse analysis approach to highlight how sexist media construct images of feminine beauty. The research argues that the image of an ideal woman presented in advertisements and other popular textualizations confines women to mere objects of desire, leisure and sex.

All the studies depict the representation of women in advertisements. Also they are discussing the impacts of advertisements on different fields of society but no study enquires the role of advertisements in creating cultural shift related to female society of Pakistan or Pakistani women forgetting their religious codes and socio- 
cultural norms due to the influence of adverts and popular figures publicising different products. This is the gap on which the present study will be based.

\section{Methodology}

For the analysis of advertisements, approach of Fairclough (1989) has been used. This approach is selected as it focuses on the text and social practice as well. In addition to this celebrity endorsement is also studied in order to show how advertisements become effective in a particular society.

\subsection{Research Design:}

The present study falls into the realm of qualitative research. A qualitative approach is suitable in this study which is investigating that how discourse in advertisements affects the audience.

\subsection{Population and Sampling}

Purposive sampling is employed because the study is investigating only fairness product advertisements. Data is collected from 10 fairness product advertisements in random from internet. These advertisements are about fairness creams, lotions, face-washes and soaps.

\subsection{Theoretical Framework}

The theoretical framework used for this study is Fairclough's Critical Discourse Analysis framework (2001). Advertisements are taken as media discourse because they involve language and social practices. This framework is used to show the connection between social practices and the properties of language (texts). Fairclough's three-dimensional framework includes a discourse as text (micro level), discursive practices (meso level) and social practices (macro level). Its aim is to discover how advertisers convince the customers to buy the products.

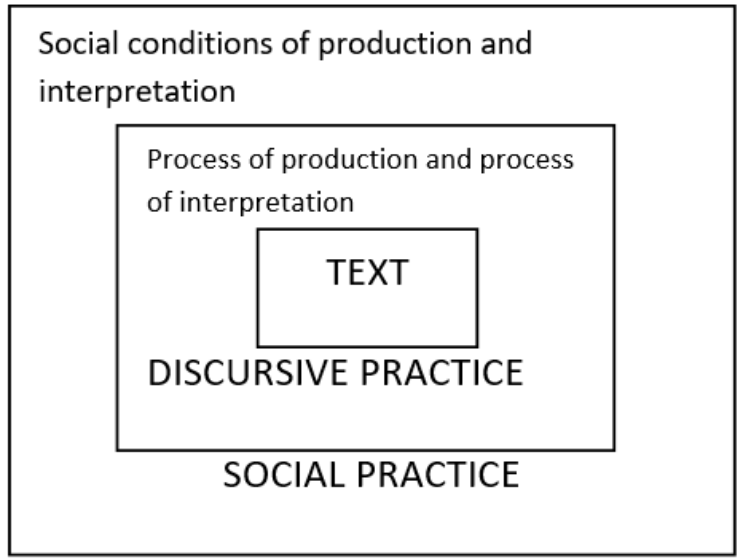

\section{Analysis \& Discussions}

This study has attempted to analyse advertisement discourse at the textual (micro), discursive practice (meso) and social practice (macro) level based on Fairclough's (2001) CDA framework. The study has analyzed twenty advertisements of fairness products collectively i.e. cream, facewashes, lotions and soaps.

\subsection{Analysis at the level of text}

The textual analysis answers the first research question i.e. language patterns in the advertisements are analysed. At this level of analysis the linguistic features such as vocabulary, syntax and rhetorical devices used in advertisements are discussed. During the study the researcher noticed a great use of direct address in the advertisements which hide the actual actors. This use is to create bonding with the target audience. The use of the second-person pronouns and possessive pronouns like 'you' and 'yours' is to address the readers directly and personally. People found it highly valuable when they are addressed individually and personally rather than collectively. Audience seems themselves in that scenario to be like those actors/actresses. This treatment of people is referred as 'synthetic personalization' (Fairclough, 1989:62). For instance:

"Increase your face value"

"Every time you use it, you get fairness....Ready to take a fairness bet with us?"

The use of first and second person pronoun indicates that the advertiser or the company is making promises which are honest and truthful. Use of pronouns at the place of verbs establishes a strong relationship between the presenter and the audience. We shows the authoritative power and you reflects a sort of personal engagement with the customer while the use of our reflects a kind of $u$ s versus them feeling i.e. in groups rather than out 
groups.

Then, to draw readers' attention and to give them confidence, questions are imposed. Such as:

Ready to take a fairness bet with us?

If you value your face, should you be washing it with soap?

Such questions set up a close association with recipients and promote a sense of inequality between customers and advertisers. Such questions in the advertisements bounds the viewers that they must purchase that product or else they are suffering from the loss. Also the advertisers know the psyche of the women so they use such questions to increase the market value of that particular product.

Another element is the use of syntax (disjunctive), that is use of phrases with no verb and subject, like;

Unbeatable fairness

Not just a cream.... It's a fairness treatments

Super effect

Fairness therapy

Fairness + dark spot reduction

Grammatical feature are also studied under the heading of textual feature. Mostly the use of adjectives is very common to give positive and negative impact. These adjectives are related to quality of products. Positive adjectives are used to emphasize the positivity of the manufacturing. Certain emotions, dreams and fantasies are aroused among women and the qualities of an ideal woman are portrayed by using these adjectives which compels the consumer to buy the product at any cost. And in this way the company increases the market value of its products and manipulate the feelings of customers especially of women.

Beauty forever, Fairness treatment, Fruity, fresh \& fair, Flawless, spotless, Pearl perfect fairness, Double action fairness, Unbeatable fairness, spot breaker

Similarly the negative adjectives are correlated to the issues that exist before the use of the product or due to not using the product and that'll be resolved after using the product.

Sensitive skin, Sunburn, Dark skin, Spotted skin

In addition, also to persuade the readers to buy or take particular actions advertisers usually need to use imperatives. The following are some examples of imperatives used in the advertisements analysed in this study.

Get clear \& youthful skin after one wash

Give your face the value it deserves

Stay beautiful

Leejiye kuchh Fresh Fruits apni jild kay liye bhi

Technical and scientific words are also used to attract readers and to reflect an image of professionalism and advancement in technology. For creating an impression on the consumers, advertisers use scientific words and information. They establish an impression that the products are scientifically proven and whatever they are saying is not only myth but the facts and also they want themselves to portray that they are up-to-date with technology. The followings are some examples.

$100 \%$ natural origin rose petal oil

Contains multivitamins

Clinically proven fairness

Dermatologically tested

With ocean botanical complex

Skin and wellness centre

With coconut, pea \& natural supplements extract

With beauty oils

Spot breaker technology

The use of poetic devices such as alliterations is quite common in the advertisements and this use makes easy for people to remember the brand, the product and the message. Such as:

Satin Soft Skin

Clean, Clear \& Glowing skin

Fairness Facewash

Pearl Perfect Fairness

Desires are induced and ideal image of beauty for women is constructed by all of these advertisements. Women like to have certain attributes within themselves that some advertisements and products contain. One of them, the most major is to have a fair complexioned skin. These advertisements spread a bogus impression that if women will use these products they will get the required and desirous features. Media in this way misleads the masses specially women.

\subsection{Analysis at the level of discursive practice}

Text's production, distribution and consumptions is analyzed at this level by considering how power relations are 
established through the text. A number of strategies are used by advertisers in their discourse to catch the attention of consumers. The table below summarizes these strategies.

\begin{tabular}{|l|l|}
\hline Strategy used in Advertisement & Linguistics Devices \\
\hline 1. Celebrity endorsement & $\begin{array}{l}\text { By using a renowned personality "Zubaida Apa" } \\
\text { Saying "Ab gora hoga Pakistan" }\end{array}$ \\
\hline 2. Scientific evidence & Clinically Proven Fairness \\
\hline 3. Code switching/mixing & Ab Makeup waly look kay liye no-makeup \\
\hline 4.Emotive words & $\begin{array}{l}\text { Clear, youthful skin, whitens, nourishes, smoothens and protects, } \\
\text { increase your face value }\end{array}$ \\
\hline
\end{tabular}

We see advertisements of numerous fairness products on television every day which are highly regressive and condemnation. Every other day you come across a new soap, a new cream and a new facewash that promise you a fairer skin. The advertising formula is simple; if you have fair and flawless skin anyone will fall in love with you instantaneously. Not only has this but girls who do not have a fair skin had no reason to be confident. These advertisements clearly show that the worth of a person is determined by his or her skin colour. Being fair means you are beautiful and if you are beautiful you can rule the world.

Fairness advertisements spread the concept of beauty according to their own perspective and in their own benefit. By advertising the products for changing one's complexion, they are creating a distorted picture of beauty i.e. beauty only means to have a fair skin tone and people with dark skin are outcaste and not beautiful at all. And they have no rights to get equal chances of career development. When you say "Dark out, White in" you are declaring that dark complexioned people are outdated and only the white toned people are acceptable, and also "increase your face value" means that if you are dark your face has less or no value.

Only fair complexion opens the doors for getting good jobs, a super-cool husband and much more. These ads are creating biases and stereotypes for black people. In this way these ads are promoting racism. As the Dove brand was accused of racism over the online advertising campaign promoting fairness body lotion showing a black woman turning into a white woman and later the brand apologised by saying it 'missed mark'. The advertisement showed a black woman removing her top to reveal a white woman underneath supposedly after using "Dove body lotion". The white woman then removes her top and turns into a Middle Eastern woman.

Women are the main audiences of fairness product advertisements because mostly they spend time at home watching TV, so they get influenced easily. The advertisers take advantage of the weaknesses of the women. Analysis has revealed that they consciously used strategies of casting famous celebrities, beautiful models, scientific evidences, code mixing, slogans and colour scheme etc. By doing this they establish the power relationship.

Actresses are presented in such a way that it seems like their beauty is just because of the use of that product. Emotive words are used in the advertisements, that the viewers interpret it in positive manner and their position in the society is reputable and people start trusting them and their product.

Adding scientific evidences is another strategy that establishes a strong relationship between advertiser and the audience. 9 When presented the products using scientific information people believe more and are persuaded to buy the product.

Number of users is increased through the technique of code switching and code mixing as a terminology in the advertisement. It leaves a strong impact on the viewers and set up a power relationship with communities speaking different languages. As a result the production, consumption and distribution in the society are increased.

Semiotics is also used to influence the audience such as fresh, vibrant and erotic colours especially red, pink, makeup of the models and images of natural ingredients i.e. roses, coconut, milk, aloe-vera and fresh fruits that are presented as to use in the manufacturing of the product. Also 2 images of the woman are presented. In back image, that is the image presented as before the use of the particular product, her face is damaged, dark and full of pimples but the front image is showing her perfect, flawless and fair skin after using the product.

The representation of positive self and negative others is also apparent when the advertisers claim that their product is beneficial; their product is better than others'.

This is how a diverse number of linguistic techniques are used to maintain a power relationship. In this way production, consumption and distribution of the product in the society increased and women are exploited by presenting them in all these techniques.

\subsection{Analysis at the Level of Social Practice}

This level of analysis clarifies the societal flows influencing ads. This is likewise about intertextual understanding that comprehends the wide cultural flows that are influencing the content being studied. This incorporates views on beauty by individuals worldwide and explicitly Pakistani ladies' place inside these practices. Ladies in the former times had utilized different conventional items to upgrade their appearance. For example, they painted their faces utilizing mud, clay, herbs, leaves, flowers etc. In this age beauty and physical 
appearance are stressed as attractive and admired. Beauty products i.e. fairness products are used to improve their physical appearance. Ladies today are so fixated on looking appealing and are happy to put forth an admirable attempt to accomplish their wants. Excellence items commercials can have control or control over purchasers.

A few ladies some of the times are misdirected in believing that what is being promoted is valid or not. As is obvious from the research, society appears to admire and value fair complexioned women more than the dark complexioned.

Identities are too shaped in the course of advertisements. The ads make women feel that so as to be 'ingroup' as opposed to 'outgroup' they should buy the product. They will be much the same as the celebrities, beautiful models or popular individuals who look great by utilizing the item. It is asserted that if you want to be as successful as these celebrities are, you have to utilize items that these well known ladies use. Also a very influential figure, Zubaida Aapa who is very famous for her home remedies for beauty, launching her own fairness soap nemed "Zubaida Aapa whitening soap", and saying “Ab Gora Hoga Pakistan" creates the impact.

Research demonstrates that fair individuals attain a preferred position over dark individuals. The idea is that appealing ladies are increasingly effective in business and personal lives as compared to less appealing ladies (Godoy et al, 2005). In this way ladies are made to feel so worried about their appearance. They are made to feel that having great appearance is extremely essential. Furthermore, the pictures of alluring models in ads bring down the self-image of buyers. However it also guarantees that the issue can be tackled by using the particular product. In short the sentiments of disappointment among consumers are aroused as a technique to invigorate buyers to buy their products to improve their looks and in the end be satisfied. A related report by Trampe et al (2011) indicates how fairness product advertisements lower female customers' confidence.

They claim that the advertising company has the ability to change ordinary items into profoundly alluring ones. Their conflict is that fairness product ads don't simply sell items yet in addition they are spreading prejudices regarding colour of the people and thus excluding the dark people from the race of success until or unless they also start using their product. In this way they are exercising the normalizing power which people consider so normal that they even rarely notice.

\section{Findings \& Conclusion}

Researcher's focus in this study is on the Language used in the advertisements of fairness products. The study has discussed the use of Linguistic features and devices to see how these ads are setting up concealed discourse among the masses in order to boost the numbers of costumers. Language use is so crucial in our daily lives. The researcher in this study has traced those techniques and devices which advertisers used in the discourse of advertisements of Fairness products in order to create normalization, such as the use of nouns in place of verbs, scientific evidences, emotive words, affective slogans, colour scheme, presence of natural ingredients, code switching, celebrity endorsement, disjunctive tone pattern and so others.

This study aimed to analyze the language of some of the advertisements of fairness products. The study reveals how advertisers establish their power relations with customers by manipulating their ideology. It may be concluded through the analysis of these advertisements that advertisers use a variety of linguistic devices such as direct address $\left(1^{\text {st }} \& 2^{\text {nd }}\right.$ person pronouns i.e. I, We, You, Us etc), positive adjectives, headings, and attractive slogans to persuade people and especially women.

It is evident from the data analysis that the most apparent idea in the advertisements is the presentation of perfect appearance for women. The findings specify that women will look perfect only when they have fair and flawless skin with no marks or scars, only then they can be successful in their personal as well as in social lives. They can get a good job, a handsome proposal and a great career only if their colour is fair. Moreover it's not very difficult to attain this. The only thing you have to do is to use a specific product that will change their whole life. In short, it is concluded that advertisers and product sellers manipulate women through their discourse buying a new way of life.

\section{References}

Abdelaal, N. M., \& Sase, A. S. (2014). Advertisement Analysis: A Comparative Critical Study. Advances in Language and Literary Studies , 5.

Advertisement Analysis: A Comparative Critical Study . (2014). Advances in Language and Literary Studies, 5. Afshan, N. (2018). Breaking Gender Stereotypes: A Multimodal Analysis of Selected Pakistani Electronic Media Advertisement. Islamabad, Pakistan.

ALI, A. H., NAZ, T., AFTAB, H., \& DANISH, M. H. (2014). Effect of Women Representation in Lux Advertisement on Pakistani Women Identity . EUROPEAN ACADEMIC RESEARCH, 14.

Ali, D. S., \& Ullah, Z. (2015). Semiotic Insight into Cosmetic Advertisements in Pakistani Print Media. INTERNATIONAL JOURNAL OF HUMANITIES AND CULTURAL STUDIES , 16.

Ghosh, S., \& Singh, R. (2019). Changing face of Indian Television Commercials: Socio-pragmatics of socially 
responsible ‘open' Slogans . Research Gate , 4.

Iqbal, A., Danish, M. H., \& Tahir, M. R. (2014). Exploitation of Women in Beauty Products of "Fair and Lovely": A Critical Discourse Analysis Study. International Journal on Studies in English Language and Literature (IJSELL) , 9.

Kaur, K., Arumugam, N., \& Yunus, N. M. (2013). Beauty Product Advertisements: A Critical Discourse Analysis. Asian Social Science, 10.

Najafian, M., \& Ketabi, S. (2011). The Words behind Images: A Critical Social Semiotic Approach toward Analyzing Advertising. International Journal of Linguistics , 21.

Riaz, I., \& Tehseem, T. (2015). Exploring the Sexual Portrayal of Women in Media Adverts: A feministic perspectiv. International Journal of Advanced Information in Arts Science \& Management, 17.

Shaikh, M., Bughio, D. F., \& Kadri, S. A. (2015). THE REPRESENTATION OF MEN AND WOMEN IN ADVERTISEMENTS: A CRITICAL DISCOURSE ANALYSIS. The Women -Annual Research Journa, 33.

Shah, M. I., \& Saher, N. (2019). CDA of Rhetorical Devices Used in Advertisements of Beauty Products in Pakistani Print Media. New Media and Mass Communication, 8.

TURHAN, B., \& OKAN, Z. (2017). Critical Discourse Analysis of Advertising: Implications for Language Teacher Education . International Journal of Languages' Education and Teaching, 13.

Ullah, H., \& Khan, H. N. (2014). The Objectification of Women in Television Advertisements in Pakistan. FWU Journal of Social Sciences , 9. 